\title{
Does Comparing Informal and Formal Procedures Promote Mathematics Learning? The Benefits of Bridging Depend on Attitudes Toward Mathematics
}

\begin{abstract}
Shanta Hattikudur, ${ }^{1}$ Pooja G. Sidney, ${ }^{2}$ and Martha W. Alibali ${ }^{2}$
${ }^{1}$ Temple University, ${ }^{2}$ University of Wisconsin-Madison

Correspondence:

Correspondence concerning this article

should be addressed to Shanta

Hattikudur, via email to

shanta.hattikudur@temple.edu.

\section{Keywords:}

mathematics, comparison, instruction, conceptual knowledge, math attitudes, algebra

\section{Acknowledgment:}

We thank Rory Raasch for assistance with data collection and coding, and we thank

Students benefit from learning multiple procedures for solving the same or related problems. However, past research on comparison instruction has focused on comparing multiple formal procedures. This study investigated whether the benefits of comparing procedures extend to comparisons that involve informal and formal procedures. We also examined how learner characteristics, including prior knowledge and attitudes toward mathematics, affect learning from comparing procedures. We addressed these issues in college students' learning procedures for solving systems of equations problems in algebra. Learners who liked mathematics learned equally well whether they received comparison or sequential instruction. However, among learners who did not like mathematics, instruction that included support for comparisons between the formal and informal procedures led to greater gains in conceptual knowledge than did sequential instruction of the procedures.
\end{abstract} the members of the Cognitive Development and Communication Laboratory for helpful discussions of this research.
Learning to solve problems is an integral part of learning mathematics. In many lessons, students are taught a single procedure for solving a particular type of problem, and this approach often leads to good learning of the taught procedure. However, research across a variety of mathematical domains suggests that students may also benefit from learning multiple procedures that can apply to the same or related problems (Rittle-Johnson \& Star, 2007; Silver, Ghousseini, Gosen, Charalambous, \& Strawhun, 2005; Star \& RittleJohnson, 2009; Star \& Seifert, 2006).

Some researchers have argued that the benefits of learning multiple procedures are especially great when students compare those procedures. Comparing procedures could be beneficial in a range of ways. Comparison may foster deeper processing of the learned procedures, which could enable more successful application of those procedures on later problems. Comparison may also highlight differences among procedures (e.g., Gentner \& Markman, 1994), which may provide people a basis for selecting the best procedure to use in a given circumstance. At the same time, comparison may also highlight similarities among procedures, and may help people to identify and evaluate those similarities. A thoughtful consideration of similarities may allow people to differentiate important similarities between procedures from alluring but more superficial ones (Cummins, 1992; Hattikudur \& Alibali, 2010; Schwartz \& Bransford, 1998). Comparison may also help people more accurately represent key features of the problems themselves. Related problem solving procedures may operate on similar or different sets of problem features (Alibali, Phillips, \& Fischer, 2009), and comparison could highlight specific features that are involved in both of the compared procedures, or features that are involved in only one of them.

By comparing procedures that realize common goals with different sets of steps, people may also be able to extract the common relational structure that underlies those procedures (Schwartz, Chase, Oppezzo, \& Chin, 2011). For example, an individual might recognize that different procedures for solving systems of equations problems all involve isolating one of the variables. In this way, comparing multiple correct procedures may provide a basis for appreciating the conceptual underpinnings of those procedures. In this way, comparing multiple procedures also fosters conceptual knowledge of the principles that underlie those procedures. This deep knowledge of the purpose of steps within a procedure may also support adapting or transferring the procedure to different types of problems (Schneider, Rittle-Johnson, \& Star, 2011).

However, despite these possibilities, empirical findings regarding the benefits of comparison are somewhat mixed. Although many studies have documented substantial benefits for comparing procedures, others have found that benefits are limited to certain subgroups of participants. Some studies have revealed negative effects of instruction in 
multiple strategies, relative to instruction in a single approach (e.g., Jitendra et al., 2007). These mixed findings raise several questions. What sorts of comparisons are helpful, for what sorts of outcomes? And are comparisons equally beneficial for all individuals? We consider each of these issues in turn.

\section{WHAT COMPARISONS ARE HELPFUL?}

Past studies of comparing solution procedures have focused on problem domains in which there are multiple formal procedures that can be used to obtain a correct solution. For example, Rittle-Johnson and Star (2007) studied the effects of comparing procedures among 7th grade students learning to solve linear equations. Participants compared the conventional procedure to a "short-cut" procedure that involved treating expressions such as $(x+1)$ as composite variables. Relative to participants who learned the procedures sequentially, participants who compared correct procedures made greater gains in procedural knowledge, which can be defined as knowledge of action sequences needed to solve problems (Hiebert \& LeFevre, 1986; Rittle-Johnson, Siegler, \& Alibali, 2001), and greater gains in procedural flexibility, which can be defined as knowledge of multiple ways to solve problems and when to use them (Star, 2005). Participants in both groups made comparable gains in conceptual knowledge, which can be defined as knowledge of general principles and of principles that underlie procedures (Crooks \& Alibali, 2014).

Likewise, Star and Rittle-Johnson (2009) studied the effects of comparing procedures among 5th and 6th grade students learning to estimate products of one-, two- and three-digit integers. Participants compared worked examples that implemented three different formal procedures: (1) round both numbers to the nearest ten and then multiply, (2) round one number to the nearest ten and then multiply, and (3) truncate each multiplicand (ignoring the ones digits), multiply the remaining numbers, and add two zeros to the final answer. Participants in this study who compared procedures made greater gains in procedural flexibility than participants who learned the procedures sequentially.

Of course, formal procedures such as these are not the only procedures people use to solve mathematics problems. Some past research has focused on the informal procedures that people invent, based on their world knowledge and general problem solving skills (Baroody \& Ginsburg, 1986; Carraher, Carraher, \& Schliemann, 1985; Koedinger \& Nathan, 2004). Informal procedures for solving mathematics problems can be defined as procedures that do not rely on mathematical formalisms (such as symbolic equations) and that are not typically acquired through classroom instruction (Koedinger \& Nathan, 2004).

Connecting informal procedures and more formal procedures may be especially beneficial for building mathematical knowledge. As Baroody and Ginsburg (1986) argued, "Informal mathematics is a foundation for learning formal mathematics. It is important for children to learn formal mathematics, because it is in many ways a more powerful tool than informal mathematics. ... However, if formal instruction fails to build on or connect to informal mathematics, children may have to rely on rote memorization and mechanical use of the new material" (p. 101). Despite the importance of connecting formal and informal knowledge in mathematics, no studies of comparing procedures have investigated the effects of comparing informal and formal procedures on problem solving and conceptual understanding. This study sought to address this gap in the literature.

\section{WHO BENEFITS FROM COMPARISON, AND ON WHAT OUTCOME MEASURES?}

Past research has also painted a varied picture of the types of outcomes that can improve via comparison (see RittleJohnson \& Star, 2011, for a review). As noted above, there is reason to expect that comparing procedures would yield benefits for procedural knowledge, and some studies have documented such benefits (e.g., Rittle-Johnson \& Star, 2007). Likewise, there is reason to expect that comparing procedure should yield gains in procedural flexibility, and a few studies have documented such gains (e.g., Star \& Rittle-Johnson, 2009; Rittle-Johnson, Star \& Durkin, 2011).

Because comparison may enable people to extract the common relational structure underlying related procedures, there is also reason to expect that comparison may yield benefits for conceptual knowledge. Indeed, a few studies have shown that comparison can foster gains in conceptual knowledge (e.g., Sidney, Hattikudur, \& Alibali, 2015). However, conceptual gains are often small and limited to a subset of participants.

Across these varying outcome measures, many studies have shown that the benefits of comparison depend on individuals' levels of prior knowledge, including their knowledge of the relevant procedures. For example, in the study by Star and Rittle-Johnson (2009), in which elementary students learned multiple procedures for computational estimation, comparing procedures promoted more lasting gains in conceptual knowledge than encountering the procedures sequentially-but only for participants who were already familiar with one of the procedures. Along similar lines, in a study of students' learning of linear equations, Rittle-Johnson, Star, and Durkin (2009) found that comparison instruction led to the best learning outcomes for students who had some prior knowledge of algebraic methods. For students who did not attempt algebraic methods at pretest, sequential instruction about the procedures was more beneficial.

These findings raise the question of whether individual characteristics other than prior knowledge might also moderate the effects of comparison instruction. In addition to cognitive factors (such as amount of prior knowledge), affective factors also influence how people engage with the learning environment (e.g., Harackiewicz, Durik, Barron, Linnenbrink-Garcia, \& Tauer, 2008; Hidi \& Renninger, 2006). Thus, it seems likely that affective factors, such as attitudes toward mathematics, might also affect how people learn from comparison. 
In past research, a positive attitude toward mathematics, and in particular, greater interest in mathematics, has been broadly linked to achievement, with correlations stronger in the later grades (Schiefele, Krapp, \& Winteler, 1992). However, the paths by which attitudes affect performance remain unclear. One study of learning from text found that the effect of attitudes on learning was mediated by persistence (Ainley, Hidi, \& Berndorff, 2002); participants with greater interest persisted longer during the learning task, and thus had more opportunities to learn. In a similar vein, in the present study, we consider the possibility that students' attitudes toward mathematics influence the ways they respond to instruction about procedures for solving mathematics problems.

Very little prior research has directly investigated the role of attitudes toward mathematics in learning from problem solving instruction, and much of this work has been exploratory. In one such study, Belenky and Nokes (2009) found that the effects of metacognitive questioning during problem solving instruction depended on participants' reported level of engagement. Among participants who were more engaged in the instruction, those who received prompts focused on the procedure learned more than those who received metacognitive prompts to promote conceptual understanding. Among those who were less engaged in the instruction, the opposite pattern was found. Belenky and Nokes argued that, for less engaged participants, the metacognitive prompts provoked deeper processing of the material, and consequently supported learning better than prompts directed at procedures. In contrast, more engaged participants processed the material deeply, even when they did not receive metacognitive prompts.

Thus, Belenky and Nokes (2009) argued that metacognitive questioning supported deeper processing for less engaged participants. Along similar lines, we might expect comparison to support deeper processing for participants who have less positive attitudes toward mathematics. In this research, we consider both prior knowledge and attitudes toward mathematics as potential moderators of the effects of comparison on problem solving and conceptual knowledge.

\section{THE CURRENT STUDY}

In this research, we address two primary research questions. First, does instruction that involves comparing an informal and a formal procedure lead to greater gains in procedural and conceptual knowledge than instruction that involves learning those same procedures separately and sequentially? That is, do the benefits of comparing procedures extend to comparisons that involve bridging informal and formal procedures? Based on past research about the effects of comparison more generally (e.g., Gentner \& Markman, 1994), we expect that they will.

Second, how do learner characteristics, including prior knowledge and attitudes toward mathematics, affect learning from comparing multiple procedures? Based on Belenky and Nokes' (2009) prior work, we expect that individuals with more negative attitudes toward mathematics may reap greater benefits from comparing procedures than individuals who have more positive attitudes toward mathematics.

We address these issues in algebra, and specifically in systems of equations problems. Solving such problems is a fundamental skill in algebra, and it is recognized in the Common Core State Standards (NGACBP \& CCSSO, 2010). In this study, we targeted a convenience sample of college students, but the general issues we focus on-linking of informal and formal procedures, and learner characteristics and learning from comparison-are applicable, both to other age groups and to other content domains within mathematics.

\section{METHOD}

\section{PARTICIPANTS}

Participants were 112 undergraduate students (73 female, 39 male) enrolled in Introductory Psychology at a large public university in the Midwestern United States. Participants received extra credit toward their course grade in exchange for their participation. The sample, reflecting the university's student body, was 64\% Caucasian, 26\% Asian, 2\% African-American, 4\% of Hispanic ethnicity, and 3\% some other category or did not report. One participant was excluded from analysis due to experimenter error, resulting in a final sample of 111. Participants were randomly assigned the two lesson groups, resulting in 58 participants in the comparison group and 53 in the sequential group.

\section{PROCEDURE}

Each participant took part in an individual experimental session that lasted approximately 30 minutes. All sessions were conducted in a laboratory room on campus, and all sessions were videotaped with the participants' consent.

The experimental session consisted of a pretest, a lesson, and a posttest, described in detail in the following sections. Participants did not receive feedback on their performance at pretest or posttest.

\section{PRETEST}

The pretest consisted of one systems of equations problem, in which participants were asked to solve for two unknown quantities (see Figure 1 in Appendix A). Solutions were coded for correctness ( 1 point for the correct price of a light bulb and 1 point for the correct price of a clock), yielding a total of 2 possible points for the pretest. Participants' responses were also coded for the procedure used to solve the problem. These procedures included substitution, combining equations, guess and check, and various incorrect procedures. Some participants left the problem blank or wrote "don't know", and some did not complete a procedure that they started, yielding no final solution; these approaches were also considered incorrect. 


\section{LESSON}

Participants were randomly assigned to one of two lesson conditions: sequential or comparison. Participants in both conditions received instruction on two solution procedures for solving systems of equations problems: first an informal procedure (trading) and then a formal procedure (matrix), described in more detail below. The same problem was used to explain both procedures (see Appendix B and C). All participants received a lesson on the informal procedure, reviewed the informal procedure on their own, and then solved a problem using the informal procedure. Participants then received a lesson on the formal procedure, reviewed the formal procedure, and then solved a problem using the formal procedure. If participants solved the problem incorrectly, they were guided to review the procedure again.

As part of the lesson, participants in each condition answered four questions about the informal and formal procedures; however, the timing and content of the questions differed between the conditions. Participants in the sequential condition answered two questions about the informal procedure after receiving instruction on the informal procedure, and answered two questions about the formal procedure after receiving instruction on the formal procedure. In this way, these participants were taught both procedures without encouraging comparisons between them. To help separate the procedures and any potential comparison between them, participants in the sequential condition completed a filler task between instruction on the informal and formal procedures. In contrast, participants in the comparison condition answered four questions after receiving instruction about both the informal and formal procedures. These questions invited participants to actively compare across the two procedures. The specific questions used in each condition are presented in Table 1 (see Appendix A). Participants then completed the filler task after instruction in both procedures.

Informal procedure. The informal procedure, the trading procedure, had been invented and explained to the researchers in a previous (unpublished) study by a 6th grade student who had not yet learned algebra. This procedure, though not integral to the previous study, was an ideal example of an invented informal procedure. It involved trading in an item from one of the sets for an item in the other set plus some amount of money. Using this trading procedure, participants could create a set that involved only one type of item. See Appendix B for the script used in presenting this informal procedure. Note that at no time during the informal lesson did the experimenter mention the concept of isolating a single variable.

After the "trading" lesson, each student was given a full minute to look over a review sheet describing the informal method. The experimenter then provided participants a practice problem to verify their understanding of the method. In the rare case that students solved this problem incorrectly, students were given time to review the procedure again before retrying the practice problem.

Formal procedure. After instruction in the informal procedure, all participants also received instruction in a formal procedure for solving systems of equations problems. Because many undergraduate students were familiar with substitution and combining equations as formal methods for solving systems of equations problems, we devised a formal procedure that involved creating and manipulating matrices to solve for the unknown variables, so that participants would be unfamiliar with the procedure. See Appendix $C$ for the script used in presenting this formal procedure.

The same problem as used in the informal procedure lesson was used again to instruct students in the formal procedure. Students were taught the procedure, given a minute to review the procedure, and then asked to solve a problem using the formal procedure to verify their ability to use the procedure correctly. Again, if students were unable to use the procedure, they were given additional time to review the formal procedure before retrying the practice problem.

Filler task. Participants in both lesson conditions also completed a spatial ability task as a filler task (Ekstrom, French, Harman, \& Dermen, 1976). For participants in the sequential condition, this task was presented in between instruction in the informal procedure and the formal procedure, so as to minimize comparison between the procedures. For students in the comparison condition, this task was presented after instruction in both the informal and formal procedures.

\section{POSTTEST}

After completing the lesson, students completed a posttest consisting of three items designed to tap procedural knowledge and three items designed to tap conceptual knowledge.

Procedural items. In the first posttest procedural item, participants were asked to solve a systems of equations problem similar to the one on the pretest. Students were instructed to use one of the procedures they had just learned to solve the problem. The problem could be readily solved using either the informal or formal procedure.

The second and third posttest items were more challenging items that required minor adaptations of the taught procedures in order to solve them correctly. For example, using the formal procedure necessitated additional procedural steps (i.e., multiplying both lines of the matrix in order to cancel). Students were instructed to use any procedure of their choosing to solve these problems. 
As for the pretest item, participants were awarded one point for a correct $x$ value and one point for a correct $y$ value for each of the posttest procedural items. Scores on the three posttest procedural items were summed to create a posttest procedural score, which could range from $0-6$ points.

Participants' responses to the posttest procedural items were also coded for the procedures used to solve the problem. These included the taught procedures (trading and matrix), as well as substitution, combining equations, guess and check, and various incorrect procedures, including leaving the problem blank, writing "don't know," not completing a procedure that they started, or leaving no final solution.

Conceptual items. The posttest also included three conceptual items. In the first of these, participants were asked to determine whether the steps in a worked example of a systems of equations problem were correct. The worked example involved an incorrect application of a substitution procedure, and noticing that the procedure is incorrect required recognizing that the steps did not result in an equation with only one variable-a process that occurred in both the trading and matrix procedures that participants learned during the lesson. Responses that simply recognized that the procedure was incorrect received one point, and responses that explained why it was wrong received two points.

In the second conceptual item, participants were shown a problem that had been solved using the trading procedure and asked to explain the purpose of the step in which a single variable is isolated. Responses that recognized that this step yielded an equation with only one variable received one point, for recognizing the isolation of a single variable. Responses that not only recognized the isolation of a single variable but also explained the purpose or goal of isolating a variable (e.g., using expressions such as "to isolate," "to eliminate," or "to get the apples by themselves") received two points.

In the third conceptual item, participants were shown a similar problem that had been solved using the formal procedure, and they were asked to explain the purpose of the step in which a single variable was isolated. Again, responses that merely recognized the isolation of a single variable received one point, and those responses that explained the purpose or goal of isolating a single variable received two points.

Scores on these three conceptual items were then summed to create a posttest conceptual score, which could range from $0-6$ points.

\section{MATHEMATICS ATTITUDE MEASURE}

As part of a demographic survey that participants completed at the beginning of the study, students rated how much they liked mathematics on a four-point scale (1 - hate math, 2 dislike math, 3 - like math, 4 - love math) (adapted from Eccles \& Wigfield, 1995).

\section{RESULTS}

\section{PRELIMINARY ANALYSES}

Pretest performance. Participants' pretest scores ranged from 0-2 (the maximum possible score), $M=.75, S D=.95$. Pretest scores did not differ by experimental condition, $t(109)=.73$, $p=.47$.

Gender and attitudes. The gender composition in each condition was comparable: $67 \%$ of participants were women in the comparison condition and $62 \%$ in the sequential condition. In light of past research documenting gender differences in students' mathematics attitudes (e.g., Hyde, Fennema, Ryan, Frost, \& Hopp, 1990) we examined whether such gender differences were present in our data. Mathematics liking scores did not differ by gender, $t(109)=.61, p=.55, M=2.65, S D$ $=.75$, and $M=2.74, S D=.75$ for women and men, respectively. Gender was not included as a factor in the main analyses.

\section{POSTTEST PERFORMANCE}

Participants' posttest scores ranged from $0-6$ on both the procedural items, $M=4.66, S D=1.73$, and the conceptual items, $M=3.10, S D=1.69$. We analyzed students' performance at posttest using a linear mixed effects model with one within-subject factor, item type (procedural vs. conceptual), and three between-subjects factors: condition (sequential vs. comparison), mathematics liking (which we dichotomized for analysis purposes, into hate/dislike vs. like/love), and pretest score (treated as continuous). All predictors were centered and all interactions were included in the model. Parameter estimates and $t$-values for the full model are presented in Table 2 (see Appendix A). Note that the findings are unchanged if mathematics liking is treated as a continuous variable, rather than a dichotomous variable.

We expected that students who liked mathematics would perform better overall than students who did not like mathematics, and this was indeed the case, $t(103)=3.58, p<.001$. In addition, because the lessons focused on procedures for solving systems of equations problems, we expected that students would perform better on the procedural items than on the conceptual items, and this was the case as well, $t(103)=5.51, p<.001$.

These main effects of mathematics liking and item type were qualified by a significant three-way interaction of mathematics liking, item type, and condition, $t(103)=2.34$, $p=.02$. Among participants who liked mathematics, participants in the sequential and comparison conditions performed similarly well, both on procedural items, $M=4.85$ and $M=4.87$ points, respectively, and on conceptual items, $M=3.73$ and $M=3.41$ points, respectively; see Figure 2 in Appendix A. Among participants who did not like mathematics, 
however, there was a significant interaction between condition and item type, $t(103)=-2.46, p=.02$. Participants in the comparison condition performed slightly worse than participants in the sequential condition on procedural items, $M=3.90$ and $M=4.40$ points, respectively, though a test of this simple effect revealed that this difference was not significant, $t(103)=-.86, p=.39$. Participants in the comparison condition performed substantially better than participants in the sequential condition on conceptual items, and a test of this simple effect was significant, $M=2.83$ and $M=1.49, t(103)=2.5, p=.01$.

Not surprisingly, better performance on the pretest item was also associated with higher scores on posttest, $t(103)=3.21$, $p=.002$. On the basis of findings from Rittle-Johnson, Star and Durkin (2009), we also expected an interaction between pretest and condition, such that this association would be stronger in the comparison condition. Although the pattern of data was as predicted, the interaction was not significant with an alpha level of $.05, t(103)=1.82, p=.07$. As expected, pretest scores were positively associated with posttest scores in the comparison condition, $b=.72, p<.001$; however, this was not the case for the sequential condition, $b=.20, p<.37$. Thus, among participants who compared procedures, those who had greater success on the pretest item displayed greater gains.

\section{PROCEDURE USE ON THE POSTTEST PROCEDURAL ITEMS}

We also examined the procedures that participants used to solve the posttest problems. The data are presented in Figure 3 (see Appendix A). With few exceptions, participants who liked mathematics used the matrix procedure and implemented it correctly, regardless of condition. In contrast, procedure use was more variable among participants who did not like mathematics. Although a majority of participants who did not like mathematics in both conditions used the matrix procedure and implemented it correctly on all three posttest problems, a substantial subset of participants applied the matrix procedure incorrectly or used the trading procedure. In the comparison condition, even participants who did not like mathematics nearly always attempted the matrix procedure, though they sometimes failed to implement it correctly. In the sequential condition, however, a subset of participants who did not like mathematics utilized the trading procedure, suggesting that in the absence of directions to compare procedures, they preferred the more meaningful, informal procedure. Of all four groups, those who did not like mathematics and who received sequential instruction were the least likely to correctly use the matrix procedure.

\section{DISCUSSION}

This study examined effects of comparing informal and formal procedures on participants' solving of systems of equations problems. We predicted that instruction that involved comparing procedures would lead to more successful problem solving than instruction that involved presenting the procedures separately and sequentially, and we expected that these effects might be moderated by individual characteristics, such as prior knowledge or attitudes toward mathematics.

These hypotheses were partially supported. There was no main effect of comparison instruction; instead, the effects of comparison instruction varied for participants who had more positive versus more negative attitudes toward mathematics. Participants who liked mathematics performed equally well whether they received comparison or sequential instruction. However, among participants who did not like mathematics, instruction that included support for comparisons between the formal and informal procedures led to greater gains in conceptual knowledge than did sequential instruction about the procedures.

Participants who did not like mathematics and who received sequential instruction were also more likely than participants in other groups to use the informal procedure to solve the posttest problems. In contrast, virtually all of the participants who liked mathematics, as well as those who did not like mathematics but who received comparison instruction, consistently used the formal procedure. Thus, comparison instruction encouraged participants who did not like mathematics to at least attempt the formal procedure. These findings suggest that, in settings where learning a formal procedure is the target of instruction, comparison may be an appropriate and valuable instructional approach.

Taken together, these findings suggest that problem solving instruction that guides people to compare formal and informal procedures may be especially useful for those individuals who have more negative attitudes toward mathematics. It may be the case that individuals who do like mathematics tend to engage in comparison processes spontaneously-and as a consequence, the comparison intervention did not "add value" over what those students spontaneously did when learning the procedures sequentially. This interpretation mirrors that of Belenky and Nokes (2009), who found that students who were highly engaged in the material did not benefit from additional support for focusing attention on underlying concepts. In contrast, people who do not like mathematics may not engage in spontaneous comparison; for these individuals, the guided comparisons between the informal and formal procedure prompted in the lesson led to greater gains in learning, especially for conceptual outcomes.

The present findings highlight the complexity of the factors that influence learning from problem solving instruction. In addition to the interaction of comparison condition, mathematics liking, and item type (conceptual vs. procedural), we also observed an overall effect of prior knowledge level, with those who had more prior knowledge showing greater gains. This trend was stronger (although not significantly so) in the comparison condition than in the sequential condition. These data highlight that both cognitive and affective factors (i.e., prior knowledge and attitudes) influence what people learn from instruction. 
It may be that participants' general level of familiarity with formal procedures for solving systems of equations problems enabled them to derive conceptual gains from comparing the formal and informal procedures. Although we did not measure whether participants were familiar with the matrix procedure, participants often attempted formal procedures such as combining equations and substitution to solve the problems at pretest, and a couple of participants even commented during the formal lesson that the matrix procedure reminded them of the combining equations procedure.

Participants used the formal procedure far more often than the informal procedure on the posttest problems, on which they were encouraged to use one of the taught procedures. At first glance, this finding is puzzling, as one might expect participants who do not like mathematics to avoid the formal procedure in favor of the informal one. However, there are several possible reasons why participants may have preferred the formal procedure. First, the matrix procedure was similar to the combiningequations procedure that many students attempted at pretest. Participants may have noted this similarity and felt more comfortable with the matrix procedure than with the trading procedure. Second, the formal procedure was taught last during the lesson, so it was fresh in participants' memories and easily accessible. Third, the questions asked during the lesson in the comparison condition may have promoted an appreciation of the formal procedure's versatile application to any systems of equations problem. Indeed, participants in the comparison condition sometimes remarked, in response to the questions posed during the lesson, that the formal procedure is more efficient in situations where the numbers are larger. Finally, participants may have come into the study with the expectation that mathematics problem solving involves formal procedures.

It is also worth noting that, in this study, participants' comparison of procedures was not directly guided. Instead, comparison was prompted with questions drawing participants' attention to similarities and differences, and was also supported by juxtaposing the procedures in time (i.e., without an intervening "filler" task). Participants were free to compare the procedures along any dimensions they wished, and some participants failed to notice that both procedures involved steps with the goal of isolating a single variable. However, our intervention did include several aspects of cognitive support thought to enhance directly guided comparison instruction (e.g., Richland, Zur, \& Holyoak, 2007), including the use of visual representations and presenting the less cognitively demanding, informal procedure first. Though the formal and informal procedures were not highly aligned in space or with language and gesture, we believe that students did make greater gains in conceptual knowledge in the comparison condition (though without a pretest measure of conceptual knowledge, we cannot be certain). With more explicit guidance about what to compare, along with adequate support for the comparison, students might make even greater gains.

A few additional limitations of this study also deserve mention. First, our measure of attitudes toward mathematics consisted of a single item, albeit one that has been widely used in past research. Future research could use a more differentiated measure of attitudes toward mathematics-one that assesses not only liking for mathematics, but also the value that participants place on mathematics and the perceived importance of mathematics in their lives. Second, most participants came to this study with some knowledge of how to solve systems of equations problems (although without knowledge of the trading or matrix procedures). We cannot be sure that our findings would generalize to participants who are encountering such problems for the first time, or to participants learning other sorts of mathematics content. Third, we focused on the effects of comparing an informal and a formal procedure; we did not include a condition that involved comparing multiple formal procedures. In future work, it would be of interest to directly compare instructional conditions that link formal and informal procedures with conditions that link multiple formal procedures, to determine what sorts of links are most beneficial.

Our findings also have implications for educational practices. Many standards-based approaches to mathematics instruction recommend instructional practices that encourage students to reflect upon and compare multiple procedures for solving problems. For example, in the Principles and Standards for School Mathematics, the National Council of Teachers of Mathematics emphasizes that students should be able to "recognize and use connections among mathematical ideas" (NCTM, 2000 , p. 64 ), and specifically notes that students should develop "a deeper understanding of how more than one approach to the same problem can lead to equivalent results, even though the approaches might look quite different" (p. 354). Our findings suggest that learners who do not make such connections spontaneously may benefit from guidance in making such connections.

In sum, this research demonstrates that the benefits of comparing procedures do extend to the case of comparing informal and formal procedures, at least for individuals who have negative attitudes toward mathematics, and who may therefore be inclined to prefer informal procedures over formal ones. Thus, this research highlights the value of comparison in promoting conceptual knowledge-something that is typically quite difficult to achieve-in individuals with negative attitudes toward mathematics. For such individuals, there appear to be substantial benefits to be gained from connecting formal, schoolbased procedures to more informal, grounded ones. 


\section{REFERENCES}

Ainley, M., Hidi, S., \& Berndorff, D. (2002). Interest, learning, and the psychological processes that mediate their relationship. Journal of Educational Psychology, 94(3), 545-561. http://dx.doi.org/10.1037/0022-0663.94.3.545

Alibali, M. W., Phillips, K. M. O., \& Fischer, A. D. (2009). Learning new problem-solving strategies leads to changes in problem representation. Cognitive Development, 24, 89-101. http://dx.doi.org/10.1016/j.cogdev.2008.12.005

Baroody, A. J., \& Ginsburg, H. P. (1986). The relation between initial meaningful and mechanical knowledge of arithmetic. In J. Hiebert (Ed.), Conceptual and procedural knowledge: The case of mathematics (pp. 75-112). Hillsdale, NJ: Erlbaum Associates.

Belenky, D. M., \& Nokes, T. J. (2009). Examining the role of manipulatives and metacognition on engagement, learning, and transfer. Journal of Problem Solving, 2(2), 102129. http://dx.doi.org/10.7771/1932-6246.1061

Carraher, T. N., Carraher, D. W., \& Schliemann, A. D. (1985). Mathematics in the streets and in the schools. British Journal of Developmental Psychology, 3, 21-29. http://dx.doi .org/10.1111/j.2044-835X.1985.tb00951.x

Crooks, N. M., \& Alibali, M. W. (2014). Defining and measuring conceptual knowledge in mathematics. Developmental Review, 1-34. http://doi.org/10.1016/j.dr.2014.10.001

Cummins, D. (1992). The role of analogical reasoning in the induction of problem categories. Journal of Experimental Psychology: Learning, Memory, and Cognition, 18(5), 11031124. http://dx.doi.org/10.1037/0278-7393.18.5.1103

Eccles, J. S., \& Wigfield, A. (1995). In the mind of the actor: The structure of adolescents' achievement task values and expectancy-related beliefs. Personality and Social Psychology Bulletin, 21(3), 215-225. http://dx.doi .org/10.1177/0146167295213003

Ekstrom, R. B., French, J. W., Harman, H. H., \& Dermen, D. (1976). Kit of factor-referenced cognitive tests. In Kit of factor-referenced cognitive tests. Princeton, NJ: Educational Testing Service.

Gentner, D., \& Markman, A. B. (1994). Structural alignment in comparison: No difference without similarity. Psychological Science, 5(3), 152-158. http://dx.doi .org/10.1111/j.1467-9280.1994.tb00652.x

Harackiewicz, J. M., Durik, A. M., Barron, K. E., LinnenbrinkGarcia, L., \& Tauer, J. M. (2008). The role of achievement goals in the development of interest: Reciprocal relations between achievement goals, interest, and performance. Journal of Educational Psychology, 100, 105-122. http:// dx.doi.org/10.1037/0022-0663.100.1.105

Hattikudur, S. \& Alibali, M. W. (2010). Learning about the equal sign: Does comparing with inequality symbols help?
Journal of Experimental Child Psychology, 107(1), 15-30. http://dx.doi.org/10.1016/j.jecp.2010.03.004

Hidi, S., \& Renninger, K. A. (2006). The four-phase model of interest development. Educational Psychologist, 41(2), 111-127. http://dx.doi.org/10.1207/s15326985ep4102_4

Hiebert, J., \& LeFevre, P. (1986). Conceptual and procedural knowledge in mathematics: An introductory analysis. In J. Hiebert (Ed.), Conceptual and procedural knowledge: The case of mathematics. Hillsdale, NJ: Erlbaum.

Hyde, J. S., Fennema, E., Ryan, M., Frost, L. A., \& Hopp, C. (1990). Gender comparisons of mathematics attitudes and affect. Psychology of Women Quarterly, 14, 299-324. http://dx.doi.org/10.1111/j.1471-6402.1990.tb00022.x

Jitendra, A. K., Griffin, C. C., Haria, P., Leh, J., Adams, A., \& Kaduvettoor, A. (2007). A comparison of single and multiple strategy instruction on third-grade students' mathematical problem solving. Journal of Educational Psychology, 99(1), 115-127. http://dx.doi .org/10.1037/0022-0663.99.1.115

Koedinger, K. R., \& Nathan, M. J. (2004). The real story behind story problems: Effects of representation on quantitative reasoning. Journal of the Learning Sciences, 13, 129-164. http://dx.doi.org/10.1207/s15327809jls1302_1

National Council of Teachers of Mathematics. (2000). Principles and standards for school mathematics. Reston, VA: Author.

National Governors Association Center for Best Practices, \& Council of Chief State School Officers. (2010). Common Core State Standards for Mathematics. Washington, DC: Authors.

Richland, L. E., Zur, O., \& Holyoak, K. J. (2007). Cognitive supports for analogies in the mathematics classroom. Science, 316, 1128-1129. http://dx.doi.org/10.1126/science .1142103

Rittle-Johnson, B., Siegler, R. S., \& Alibali, M. W. (2001). Developing conceptual understanding and procedural skill in mathematics: An iterative process. Journal of Educational Psychology, 93, 346-362. http://dx.doi .org/10.1037/0022-0663.93.2.346

Rittle-Johnson, B., \& Star, J. R. (2007). Does comparing solution methods facilitate conceptual and procedural knowledge? An experimental study on learning to solve equations. Journal of Educational Psychology, 99(3), 561574. http://dx.doi.org/10.1037/0022-0663.99.3.561

Rittle-Johnson, B., \& Star, J. R. (2011). The power of comparison in learning and instruction: Learning outcomes supported by different types of comparisons. The Psychology of Learning and Motivation, 55, 199-225. http://dx.doi .org/10.1016/B978-0-12-387691-1.00007-7

Rittle-Johnson, B., Star, J. R., \& Durkin, K. (2009). The importance of prior knowledge when comparing examples: 
Influences on conceptual and procedural knowledge of equation solving. Journal of Educational Psychology, 101(4), 836-852. http://dx.doi.org/10.1037/a0016026

Rittle-Johnson, B., Star, J. R., \& Durkin, K. (2011). Developing procedural flexibility: Are novices prepared to learn from comparing procedures? British Journal of Educational Psychology, 82(3), 436-455. http://dx.doi .org/10.1111/j.2044-8279.2011.02037.x

Schiefele, U., Krapp, A., \& Winteler, A. (1992). Interest as a predictor of academic achievement: A meta-analysis of research. In K. A. Renninger, S. Hidi, \& A. Krapp (Eds.), The role of interest in learning and development (pp. 183212). Hillsdale, NJ: Lawrence Erlbaum Associates.

Schneider, M., Rittle-Johnson, B., \& Star, J. R. (2011). Relations among conceptual knowledge, procedural knowledge, and procedural flexibility in two samples differing in prior knowledge. Developmental Psychology, 47(6), 1525-1538. http://dx.doi.org/10.1037/a0024997

Schwartz, D. L. \& Bransford, J. D. (1998). A time for telling. Cognition and Instruction, 16(4), 475-522. http://dx.doi .org/10.1207/s1532690xci1604_4

Schwartz, D. L., Chase, C. C., Oppezzo, M. A., \& Chin, D. B. (2011). Practicing versus inventing with contrasting cases: The effects of telling first on learning and transfer. Journal of Educational Psychology, 103(4), 759-775. http://dx.doi .org/10.1037/a0025140

Sidney, P. G., Hattikudur, S., \& Alibali, M. W. (2015). How do contrasting cases and self-explanation promote learning? Evidence from fraction division. Learning \& Instruction, 40, 29-38. http://dx.doi.org/10.1016/j learninstruc.2015.07.006

Silver, E. A., Ghousseini, H., Gosen, D., Charalambous, C., \& Strawhun, B. (2005). Moving from rhetoric to praxis: Issues faced by teachers in having students consider multiple solutions for problems in the mathematics classroom. Journal of Mathematical Behavior, 24, 287-301. http://dx.doi.org/10.1016/j.jmathb.2005.09.009

Star, J. R. (2005). Reconceptualizing procedural knowledge. Journal for Research in Mathematics Education, 36(5), 404-411.

Star, J. R., \& Rittle-Johnson, B. (2009). It pays to compare: An experimental study on computational estimation. Journal of Experimental Child Psychology, 102(4), 408-426. http:// dx.doi.org/10.1016/j.jecp.2008.11.004

Star, J. R., \& Seifert, C. (2006). The development of flexibility in equation solving. Contemporary Educational Psychology, 31(3), 280-300. http://dx.doi.org/10.1016/j .cedpsych.2005.08.001 


\section{APPENDIX A}

Table 1.

Study questions by condition.

\begin{tabular}{|l|l|}
\hline Sequential & Contrasting \\
\hline $\begin{array}{l}\text { Do you think the trading method is a good way } \\
\text { to solve this problem? }\end{array}$ & In what ways are these two methods alike? \\
\hline When might you use this method? & How are they different? \\
\hline $\begin{array}{l}\text { Do you think the matrix method is a good way } \\
\text { to solve this problem? }\end{array}$ & $\begin{array}{l}\text { Why might it be better to use the trading } \\
\text { method? }\end{array}$ \\
\hline When might you use this method? & $\begin{array}{l}\text { Why might it be better to use the matrix } \\
\text { method? }\end{array}$ \\
\hline
\end{tabular}

Table 2.

Parameter estimates from the linear mixed effect model of participants' posttest scores.

\begin{tabular}{|l|l|l|l|}
\hline Effect & Estimate $(\boldsymbol{b})$ & $\boldsymbol{t}$-value & $\boldsymbol{p}$-value \\
\hline Condition & -.25 & -.83 & .41 \\
\hline Math liking & $1.10^{*}$ & 3.58 & $<.01$ \\
\hline Item type & $1.37^{*}$ & 5.51 & $<.01$ \\
\hline Pretest & $.46^{*}$ & 3.21 & $<.01$ \\
\hline Condition x liking & -.03 & -.04 & .97 \\
\hline Condition x item type & -.75 & -1.50 & .14 \\
\hline Condition x pretest & .52 & 1.82 & .07 \\
\hline Liking x item type & -.60 & -1.32 & .19 \\
\hline Liking x pretest & -.06 & -.21 & .84 \\
\hline Item type x pretest & .36 & 1.59 & .19 \\
\hline Condition x liking x item type & $2.32^{*}$ & 2.34 & .02 \\
\hline Condition x liking x pretest & -.74 & -1.29 & .20 \\
\hline Condition x pretest x item type & $<.01$ & $<.01$ & 1.00 \\
\hline Liking x pretest x item type & -.06 & -.13 & .90 \\
\hline Condition x liking x item type x pretest & -.20 & -.22 & .83 \\
\hline
\end{tabular}

Note. Degrees of freedom are $d f=103$ for all tests. All variables in this model are centered.

Starred values are significant at $a=.05$. 
Figure 1.

Pretest systems of equations problem.

The total cost of these items is $\$ 57$.

The total cost of these items is $\$ 80$.

Figure 2.

Posttest scores (adjusted for pretest scores) for participants who do and do not like mathematics by condition and item type. Error bars represent the standard error of each estimated mean.

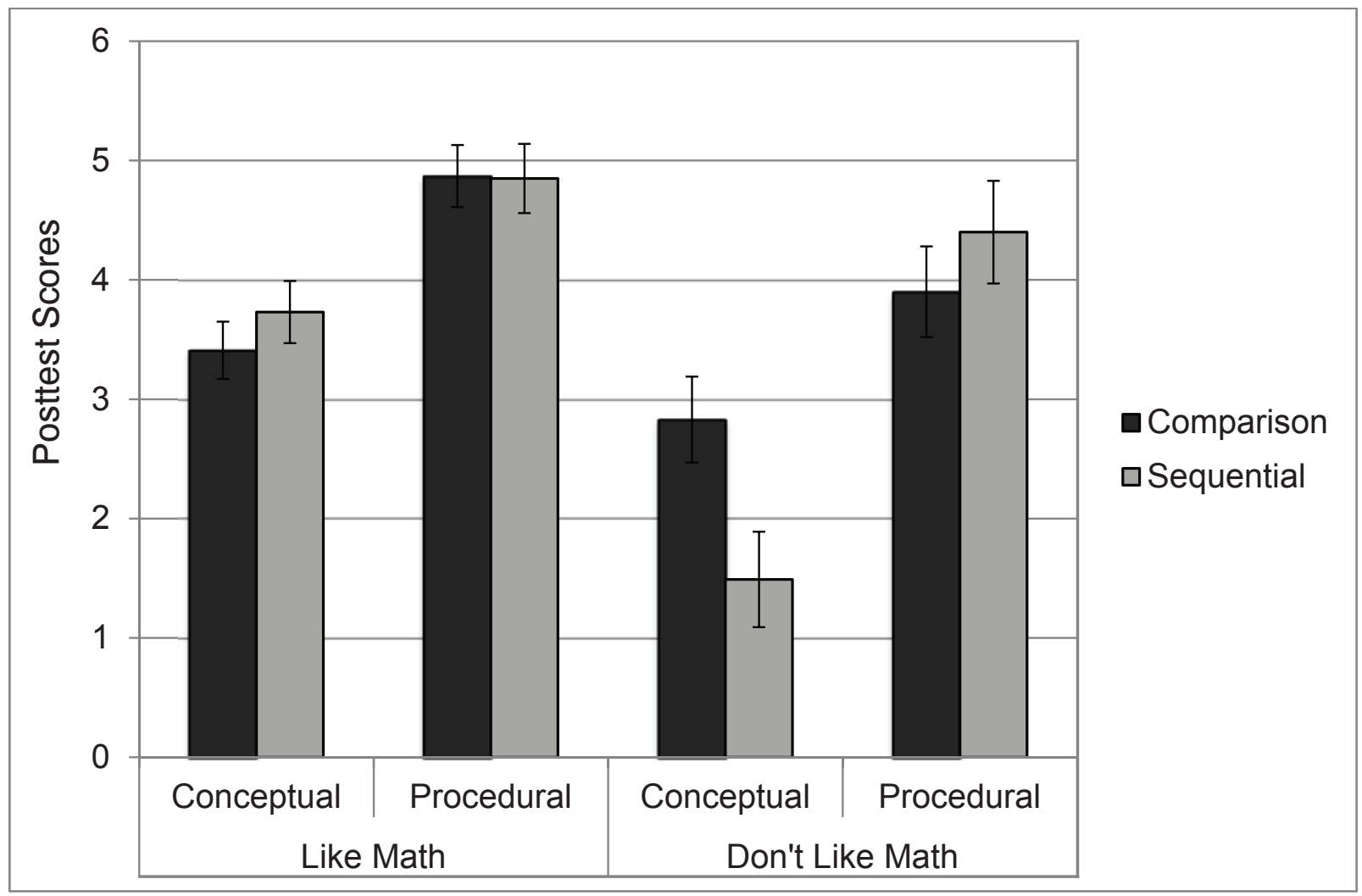


Figure 3.

Procedure use on the posttest items.

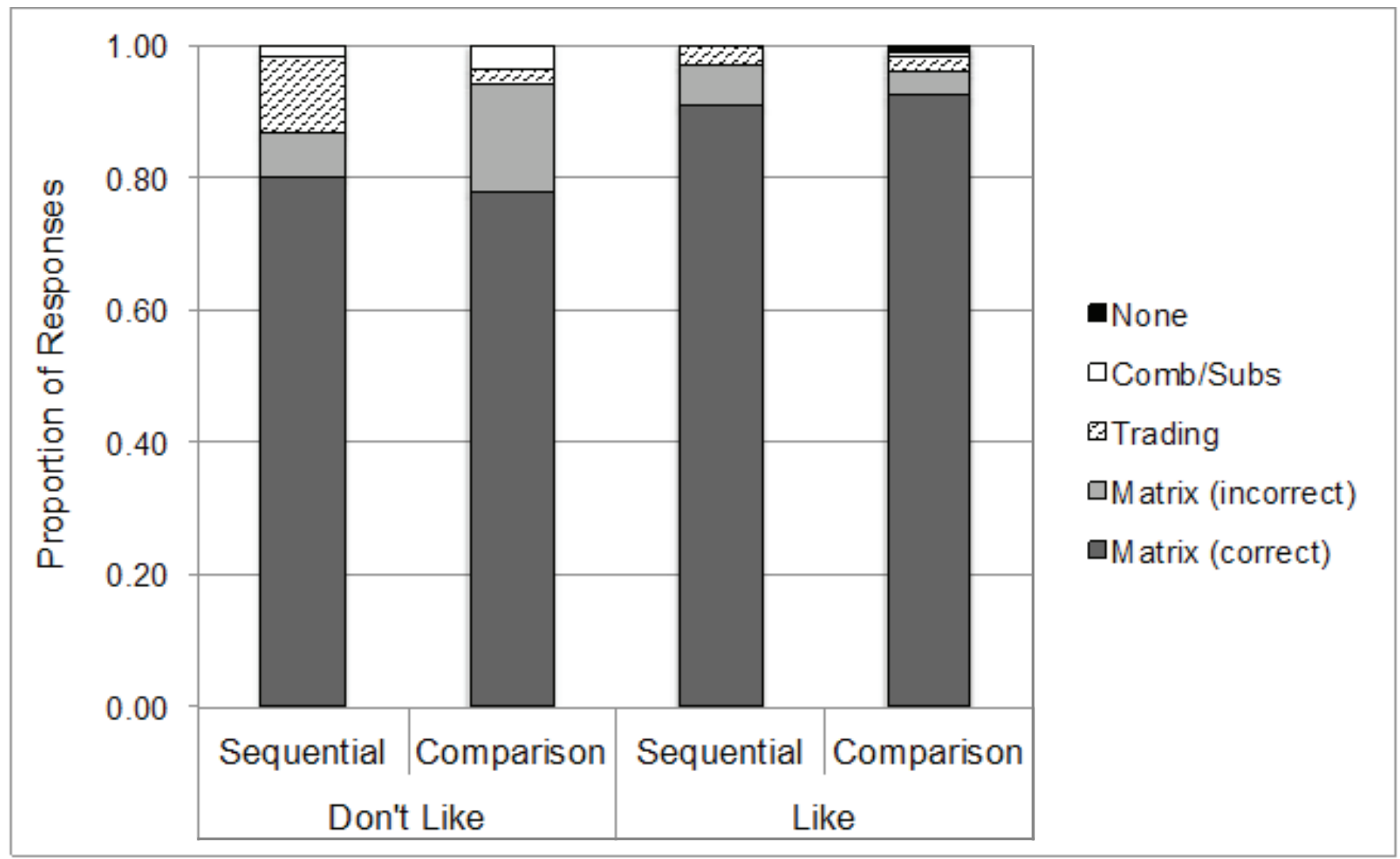




\section{APPENDIX B}

\section{INFORMAL PROCEDURE FOR SOLVING SYSTEMS OF EQUATIONS PROBLEMS}

Today we are going to talk about one way to figure out the price of items if you know the total cost of certain purchases.

In this first example: for two apples and one watermelon, the total cost for these items is $\$ 6$. For one apple and two watermelons, the total cost for these items is $\$ 9$. [Either place or point to apples and watermelons and write or point to "The total cost of these items is \$7"]

In order to find out how much one apple or one watermelon costs, one way to use the information you have is to compare the two purchases in terms of the differences in items and total cost.

So in this example, since both purchases include one apple [point to one apple in each total] and one watermelon [point to one watermelon in each total], that leaves us with one apple here and one watermelon there. [Draw an arrow from the apple to the watermelon.] Does that make sense?

Now let's look at the difference in total cost. Between this total $\$ 6$ and this total $\$ 9$, this second purchase is $\$ 3$ more. [Write +3 next to the total cost side of things.] This makes sense, right?

So now since we have one apple here and one watermelon here, one way to understand this is to say, "For every time we trade in an apple for a watermelon, we pay $\$ 3$ more."
Basically this tells us that every time you trade in an apple [point to apple in first purchase] for a watermelon [point to watermelon in second purchase] it costs $\$ 3$ more. Or in other words, a watermelon costs $\$ 3$ more than an apple. [Write +3 next to the arrow from the apple to the watermelon.]

Now that we know this, we can try one more trade. So now let's trade in this apple for a watermelon. [Place items for 3rd purchase to make it salient.] Like we said just a moment before, every time we trade in an apple for a watermelon, we pay $\$ 3$ more." So now that we've traded in this apple for a watermelon [point to items as you mention them], the total cost of these items is going to be $\$ 9$ plus $\$ 3$ or $\$ 12$ [write this equation]. So the price of 3 watermelons is $\$ 12$.

To get the price of one watermelon, all we have to do is divide the total cost by three. 12 divided by 3 is 4 , so the price of one watermelon is $\$ 4$ [write this down].

So now that we know the price of a watermelon, we can figure out the price of an apple. Let's go back to the second purchase. One apple and two watermelons was $\$ 9$. We know that each watermelon is $\$ 4$ [write 4 under each watermelon], so for two it costs $\$ 8$ [draw a line connecting the two fours and write 8]. Since the total was $\$ 9$ [rewrite below parallel to the 8], that leaves one dollar for the price of the apple. Make sense?

We can always check this using the first purchase. Two apples at $\$ 1$ a piece adds to $\$ 2$, and add $\$ 4$ for the watermelon to make $\$ 6$. That's right! 


\section{APPENDIX B, CONT'D}

(1) The total cost of these items is $\$ 6$.

$$
\begin{array}{r}
\downarrow \\
+3
\end{array}
$$
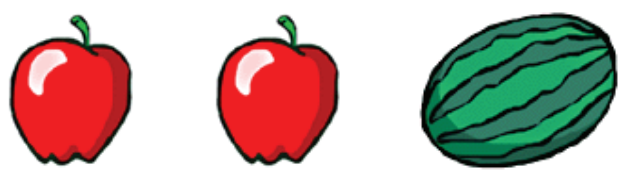

$+3$

(2) The total cost of these items is $\$ 9$.
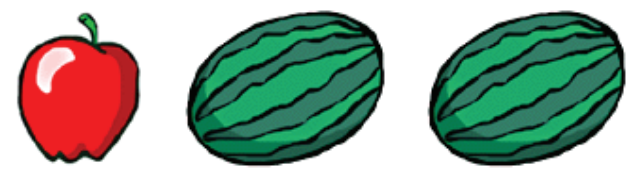

\section{What is the price of one watermelon?}<smiles></smiles>

The total cost of these items is $\$$
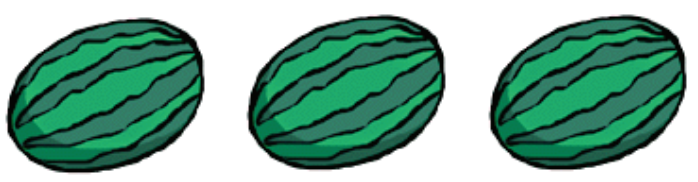

3 watermelons cost $\$ 12$.

One watermelon is $\$ 4$.

What is the price of one apple?

The total cost of these items is $\$$.

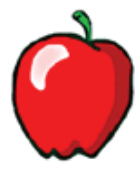

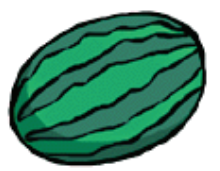

$\$ 4$

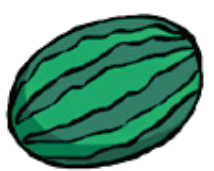

$\$ 4$

$\$ 9-\$ 8=\$ 1$

One apple is $\$ 1$. 


\section{APPENDIX C}

\section{FORMAL PROCEDURE FOR SOLVING SYSTEMS OF EQUATIONS PROBLEMS}

Now we are going to talk about another way to figure out the price of certain items using the information we are given. We can see that we have been given a number of apples [point to "a"], a number of watermelons [point to "w"], and the total cost of these items [point to "total"]. Now we can write a row to represent the first set of items: apples [point to "2"], watermelons [point to " 1 "], and the total cost [point to "6"]. We can also write a row for the second set of items [point to the second row].

So now that we know this information [gesture to the matrix you've just created], we can use this to find the price of an apple [point to first row of second matrix] and a watermelon [point to second row of the matrix].

(1) The total cost of these items is $\$ 6$.
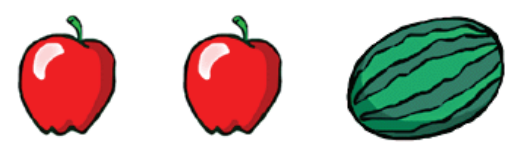
multiplying through by 2 . That gives us a 4,2 , and 12 . Now when we subtract the second row from this first row to get a 3 , a 0 , and a 3 , we can divide this row by 3 now to get a 1 , a 0 , and a 1 . So the price of one apple [gesture from the 1 back to the "a" in the first matrix] is $\$ 1$ [gesture from "total" back to 1.]

Now that we know the price of one apple, let's find the price of a watermelon. This time we can multiply the second row by 2 to get 2,4 , and 18 . Again, if we subtract the two rows, then we get a $0, a-3$, and a -12 . Now all we have to do is divide this row by -3 to get 0,1 , and 4 . So now we know the price of one watermelon [gesture back to the " $w$ "] is $\$ 4$.

We can check this using the first purpose. Two apples at $\$ 1$ a piece [write 1 over each apple] is $\$ 2$, and add $\$ 4$ for the watermelon [write 4 over the watermelon] to make $\$ 6$. That's right!

(2) The total cost of these items is $\$ 9$.
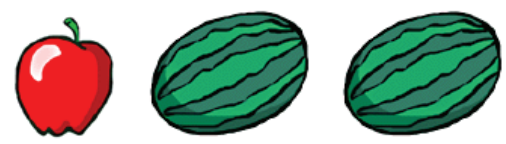

What is the price of one apple? What is the price of one watermelon?

$\begin{array}{llllll}\text { a } & \text { w } & \text { total } & \text { a } & \text { w } & \text { total } \\ 2 & 1 & 6 & 1 & 0 & ? \\ 1 & 2 & 9 & 0 & 1 & ?\end{array}$

Step 1: $\quad 4212$

$\begin{array}{lll}1 & 2 & 9\end{array}$

Step 2: $\quad 30 \quad 3$

$\begin{array}{llll}\text { Step 3: } & 1 & 0 & 1\end{array}$

One apple is $\$ 1$.

$\begin{array}{lll}2 & 1 & 6 \\ 1 & 2 & 9\end{array}$

Step 4: $\quad 2 \quad 1 \quad 6$

$\begin{array}{lll}2 & 4 & 18\end{array}$

Step 5: $\quad 0 \quad-3 \quad-12$

Step 6: $\quad \quad \quad 0 \quad 1 \quad 4$

One watermelon is $\$ \mathbf{4}$. 